\title{
Effect of routine duloxetine administration in the early postoperative period on post- prostatectomy stress incontinence in patients undergoing laparoscopic radical prostatectomy
}

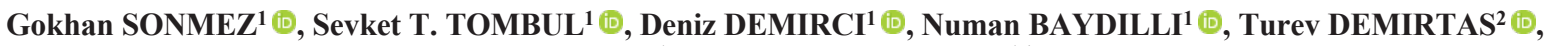 \\ Serhan ARMAN ${ }^{1}$, Abdullah DEMIRTAS ${ }^{1, * *(\mathbb{D}}$ \\ ${ }^{1}$ Department of Urology, Faculty of Medicine, Erciyes University, Kayseri, Turkey \\ ${ }^{2}$ Department of Medical History and Ethics, Erciyes University, Kayseri, Turkey
}

\begin{abstract}
Received: 08.02 .2021
Accepted/Published Online: 01.03 .2021

$\bullet$

Final Version: 23.04.2021

Abstract

Post-prostatectomy stress incontinence (PPI) is an important health problem for patients with radical prostatectomy history. Duloxetine is a common drug, used in PPI with the out of indications in most countries. In this study, we aimed to evaluate the prophylactic effect of duloxetine administration in PPI during the early postoperative period in patients undergoing laparoscopic radical prostatectomy (LRP). The retrospective study included 209 patients who underwent LRP. Patients were divided into two groups: Group I ( $\mathrm{n}=96)$ was initiated on pelvic floor exercises $(\mathrm{PFE})+$ duloxetine in the early postoperative period and continued this regimen for a total of 12 weeks and Group II ( $\mathrm{n}=113)$ only performed PFE for 12 weeks after surgery. Exclusion criteria were as follows: a history of neuromuscular dysfunction of bladder, post-prostatectomy urge incontinence, receiving adjuvant radiotherapy during the 12-week period, prior anti-incontinence surgery, and post-voiding urine $>100 \mathrm{ml}$. The prevalence rates of urinary incontinence measured at the time of urinary catheter removal (baseline) and at weeks 3, 6, and 12 after surgery and the number of wet pads per day were compared. The study included 209 patients with a mean age of $60.68 \pm 7.16$ years. Baseline urinary continence rates were similar in Group I and Group II (29.2\% vs. 35.4\%, $p=0.338)$. At 12 weeks, although PPI rates have decreased in both groups, there was no difference between Group I and Group II (15.6\% vs. $24.8 \%, p=0.103)$. Administration of prophylactic duloxetine in the early postoperative period, which started without regard to the positivity of PPI, is not significantly effective to early postoperative urinary continence recovery.
\end{abstract}

Keywords: post-prostatectomy incontinence, duloxetine, radical prostatectomy, prostate cancer

\section{Introduction}

Post-prostatectomy stress incontinence (PPI) is a significant factor leading to reduced quality of life after prostatectomy (Trofimenko et al., 2017). Although it has been reported that the majority of such patients recover continence within three months after surgery, $7-25 \%$ of patients have been shown to have persistent urinary incontinence following radical prostatectomy (Holm et al., 2014; Pompe et al., 2017; Borges et al., 2019; Kania et al., 2019).

Pelvic floor exercises (PFE) constitute the primary step in PPI treatment (Sandhu et al., 2019). Patients are recommended to perform these exercises both before and immediately after radical prostatectomy (de Lira et al., 2019). However, for patients that do not benefit from these exercises, there are limited pharmacotherapy options and thus surgical intervention (bulking agents, male slings, or artificial urinary sphincters) may be needed (Nambiar et al., 2018; Nestler et al., 2019). Duloxetine is a selective serotonin (5-HT)norepinephrine (NE) reuptake inhibitor and exerts its effect by increasing the activity of the urethral sphincter (Neff et al., 2013). This agent has been used in female stress urinary incontinence (SUI) in Europe since 2004 (Boy et al., 2006). Nevertheless, although duloxetine is recommended by some researchers, it has not been licensed in many countries (Fink et al., 2008; Collado et al., 2011; Neff et al., 2013; Gresty et al., 2019).

The present study was designed to evaluate the prophylactic effectiveness of duloxetine administration on PPI during the early postoperative period after laparoscopic radical prostatectomy (LRP) by comparing patients receiving and not receiving duloxetine regardless of their urinary continence status.

\section{Patients and methods}

\subsection{Study design and patients characteristics}

The retrospective study included 209 patients with prostate cancer who underwent LRP in Erciyes University Department of Urology between January 2011 and April 2020. The patients were divided into two groups based on the administration of duloxetine: Group I $(n=96)$ was initiated on PFE + prophylactic duloxetine in the early postoperative period (5-7 days before catheter removal) and continued this regimen for a total of 12 
weeks after surgery and Group II ( $\mathrm{n}=113)$ only performed PFE for 12 weeks after surgery.

In Group 1, duloxetine was administered at a dose of $1 \times 40$ $\mathrm{mg}$ /day for the first week and at a dose of $2 \times 40 \mathrm{mg} /$ day for the latter weeks. At the end of the 12th postoperative week, duloxetine treatment was discontinued. After waiting 3-4 weeks, duloxetine was re-recommended for patients with urinary incontinence and who wanted to start treatment again. Urinary incontinence data were recorded in both groups throughout the 12-week period. 16 (14.3\%) patients who had started duloxetine but had reported adverse events and discontinued the drug were excluded. Other exclusion criteria were as follows: incomplete follow-up records for the 12-week period, discontinuation of duloxetine due to side effects before the completion of the 12-week period, failure to initiate duloxetine therapy 5-7 days before urinary catheter removal, a history of neuromuscular dysfunction of bladder, postprostatectomy urge incontinence, receiving adjuvant radiotherapy during the 12-week period, history of overactive bladder detected on urodynamic examination, prior antiincontinence surgery, and post-voiding urine $>100 \mathrm{ml}$.

In our clinic, PFE are routinely initiated in the early postoperative period. Accordingly, the patients that did not start these exercises within this period or performed the exercises irregularly were also excluded from the study. Demographic and clinical characteristics were recorded for each patient. Additionally, the prevalence rates of urinary incontinence measured at the time of urinary catheter removal (baseline) and at weeks 3, 6, and 12 after surgery and the number of wet pads per day were also recorded. In this study, "the need to use a pad or a diaper" is accepted as urinary incontinence and patients were defined according to daily pad need (e.g., $0-1,2,3,4$ or more).

\subsection{Statistical analysis}

Data were analysed using SPSS 22.0 for Windows (IBM Corp. Released 2013, Armonk, USA). Normal distribution of quantitative data was assessed using Shapiro-Wilk test and Histogram plots. Quantitative data with normal distribution were expressed as mean \pm standard deviation (SD) and data with non-normal distribution were expressed as median (1st3 rd quartile). Categorical data were expressed as percentages (\%). Continuous variables in independent groups were compared using independent samples t-test or Mann-Whitney $\mathrm{U}$ test based on their distribution pattern. Categorical variables were compared using chi-square test (Pearson's Chi-square test or Fisher's Exact test). A $p$ value of less than 0.05 was considered significant.

This study was approved by the Erciyes University Clinical Research Ethics Committee (Approval number: 2020/078). All participants were informed verbally and in writing before the operations and a written consent was obtained from each of them.

\section{Results}

The 209 patients had a mean age of $60.68 \pm 7.16$ years, a median body mass index (BMI) of $27.5(25.5-29.5) \mathrm{kg} / \mathrm{m}^{2}$, and a median prostate specific antigen (PSA) level of $0.010(0.004-$ $0.127) \mathrm{ng} / \mathrm{ml}$ (Table 1).

Table 1. Demographic and clinical characteristics of the patients

\begin{tabular}{|l|c|c|c|}
\hline & Group 1 (n=96) & Group 2 (n=113) & $p$ \\
\hline Age (years) & $60.10 \pm 7.64$ & $61.17 \pm 6.72$ & 0.286 \\
\hline $\begin{array}{l}\text { BMI (kg/m2) } \\
\text { PSA (ng/ml) }\end{array}$ & $\begin{array}{c}\text { (28.7 }(26.2-29.5) \\
(0.006-0.145)\end{array}$ & $\begin{array}{c}27.1(25.6-29.1) \\
(0.003-0.105)\end{array}$ & 0.062 \\
\hline $\begin{array}{l}\text { Local recurrence } \\
\text { (n, \%) }\end{array}$ & $21(21.9 \%)$ & $17(15.0 \%)$ & 0.113 \\
\hline $\begin{array}{l}\text { Distant metastasis } \\
\text { (n, \%) }\end{array}$ & $4(4.2 \%)$ & $5(3.5 \%)$ & 0.429 \\
\hline $\begin{array}{l}\text { Bladder neck } \\
\text { contracture (n, \%) }\end{array}$ & $2(2.1 \%)$ & $2(1.8 \%)$ & 0.642 \\
\hline BMI: Body mass index, PSA: Prostate-specific antigen & \\
\hline
\end{tabular}

The mean baseline prevalence rate of urinary incontinence was similar in Group I and II ( $29.2 \%$ vs. $35.4 \%, \mathrm{p}=0.338)$. The PPI at postoperative weeks 3,6 , and 12 rates were similar in Group I and Group II (Table 2).

Table 2. Postprostatectomy stress incontinence rates of the groups

\begin{tabular}{|c|c|c|c|}
\hline & $\begin{array}{c}\text { Group 1 } \\
(\mathbf{n = 9 6})\end{array}$ & $\begin{array}{c}\text { Group 2 } \\
(\mathbf{n = 1 1 3})\end{array}$ & $\boldsymbol{p}$ \\
\hline Baseline (n, \%) & $28(29.2 \%)$ & $40(35.4 \%)$ & 0.338 \\
\hline Week 3 (n, \%) & $20(20.8 \%)$ & $36(31.9 \%)$ & 0.073 \\
\hline Week 6 (n, \%) & $16(16.7 \%)$ & $31(27.4 \%)$ & 0.063 \\
\hline Week 12 (n, \%) & $15(15.6 \%)$ & $28(24.8 \%)$ & 0.103 \\
\hline
\end{tabular}

PPI was positive in 43 (20.6\%) patients over the 12-week period, including $19(9.1 \%)$ patients with mild PPI (0-1 pads/day), 18 (8.6\%) with moderate PPI (2-3 pads/day), and 6 (2.9\%) patients with severe PPI ( $\geq 4$ pads/day). Moreover, no significant difference was found between the two groups with regard to PPI severity. Table 3 presents the patterns and severity of urinary incontinence in PPI-positive patients.

Table 3. Urinary incontinence patterns

\begin{tabular}{|c|c|c|c|}
\hline & $\begin{array}{c}\text { Group 1 } \\
(n=96)\end{array}$ & $\begin{array}{l}\text { Group } 2 \\
(n=113)\end{array}$ & $p$ \\
\hline $\begin{array}{l}\text { Mild PPI } \\
\text { (0-1 pads/day) }\end{array}$ & $7(7.3 \%)$ & $\begin{array}{c}12 \\
(10.6 \%)\end{array}$ & 0.482 \\
\hline $\begin{array}{l}\text { Moderate PPI } \\
\text { (2-3 pads/day) }\end{array}$ & $7(7.3 \%)$ & $\begin{array}{c}11 \\
(9.8 \%)\end{array}$ & 0.689 \\
\hline $\begin{array}{l}\text { Severe PPI } \\
\text { ( }>4 \text { pads/day) }\end{array}$ & $1(1 \%)$ & $5(4.4 \%)$ & 0.101 \\
\hline
\end{tabular}

Urinary incontinence developed in two patients in Group-1 after duloxetine treatment was stopped. Thus, after the duloxetine treatment was stopped, the incontinence rates of the groups were $17.7 \%$ and $24.8 \%$, respectively $(\mathrm{p}=0.224)$.

\section{Discussion}

The present study evaluated the effect of duloxetine in prostate cancer patients undergoing LRP over a 12-week period and revealed that the administration of prophylactic duloxetine in the early postoperative period did not decrease the prevalence rate of urinary incontinence. 
There are several studies in the literature reporting on the efficacy of duloxetine in PPI treatment (Zahariou et al., 2006; Filocamo et al., 2007; Fink et al., 2008; Collado et al., 2011; Cornu et al., 2011; Neff et al., 2013; Alan et al., 2015). Zahariou et al. conducted one of the earliest of these studies in 2006, which evaluated 18 PPI-positive patients and reported that the administration of duloxetine led to significant improvement in urodynamic parameters at the end of a threemonth period (Zahariou et al., 2006). A placebo-controlled study conducted by Filocamo et al. (2007) evaluated 112 PPIpositive patients and revealed that the administration of duloxetine allowed early postoperative urinary continence recovery. Another study that was conducted on 49 PPI-positive patients in 2008 showed that the administration of duloxetine twice daily resulted in effective outcomes in the patients (Neff et al., 2013). In our study, unlike the studies abovementioned, duloxetine administration was initiated in the early postoperative period (i.e., 5-7 days before the catheter removal) regardless of the urinary incontinence status of the patients to evaluate the prophylactic effect of duloxetine. The results indicated that the mean baseline, postoperative weeks 3,6 , and 12 prevalence rates of urinary incontinence was similar in Group I and II. In addition, urinary incontinence started only in two patients after discontinuation of duloxetine. According to these data, it is not an effective and rational method to give prophylactic duloxetine treatment to all patients undergoing radical prostatectomy. Pompe et al. (2017) evaluated a large cohort of 8,573 patients undergoing radical prostatectomy due to prostate cancer and found that almost $25 \%$ of the patients were PPI-positive at the end of the 12 -week period after surgery. However, the authors did not include patients with 0-1 pads/day in the study. In contrast, Holm et al. (2014) reported that the rate of PPI positivity was $74.1 \%$, among whom $40 \%$ of the patients used one pad daily. Nevertheless, it is worth noting that no PFE were performed by the patients in that study. Stanford et al. (2000) reported that $14.3 \%$ of the patients used three or more pads per day and no bladder control in $5.4 \%$ of the patients. Taken together, these findings implicate that there is a wide range of PPI rates reported after radical prostatectomy in the literature. In our study, the rate of SUI was $32.5 \%$ in the early postoperative period (i.e. immediately after urinary catheter removal) and decreased consistently over the 12 -week period and declined to $15 \%$ in the PFE + duloxetine group (Group I) and to $25 \%$ in the PFE-only group (Group II) at the end of the 12-week period. These rates were slightly higher than those reported in the literature, which could be attributed to the inclusion of patients who had dribbling urinary incontinence ( $0-1$ pads/day) in the study. When these patients were excluded from the statistics, the overall rate of urinary incontinence with $\geq 2$ pads/day was revealed as $11.4 \%$, which was consistent with the literature. Previous studies indicated that the number of pads per day in PPI-positive cases decreased significantly regardless of duloxetine administration over the periods ranging between three and 12 months (Stanford et al., 2000; Pompe et al., 2017). Filocamo et al. (2007) reported that the administration of duloxetine over a period of 16 weeks led to a significant decrease in the prevalence of PPI. Zahariou et al. (2006) reported that the administration of duloxetine led to significant improvement in urodynamic parameters at the end of a sixmonth period. In our study, the prevalence of urinary incontinence declined from $29 \%$ to $15 \%$ in the PFE + duloxetine group at the end of the 12 -week period. Similarly, the prevalence of urinary incontinence decreased from $35.4 \%$ to $24.8 \%$ in the PFE-only group. These reductions were statistically significant and compatible with the literature.

In the literature, the discontinuation rates of duloxetine treatment due to side effects vary between $14-35 \%$. According to a recent meta-analysis, the discontinuation rates of duloxetine treatment due to side effects were reported as $17 \%$ (Li et al., 2013). Collado et al. (2011) reported that, 25\% of patients stopped the duloxetine treatment because of adverse effects. However, in that study, patients used duloxetine for 9 months. In our study, in accordance with the literature, overall $16(14.3 \%)$ patients reported adverse events and discontinued the drug. Our study had several important limitations. Primarily, the study had a retrospective design and thus the evaluation of SUI was solely based on the numbers of pads used per day. It should be noted that the pet test is a subjective test that can vary from patient to patient. On the contrary, it is commonly known that besides the number of pads, there are some indicators/tools used in the evaluation of SUI including changes in pad weight, bladder diary, questionnaires used for the assessment of quality of life such as Urinary Incontinence Quality of Life Scale (IQOL) and uroflowmetric parameters (maximum flow rate, post-voiding residual urine, etc.). Second, no urodynamic findings were available in the study and thus our results were solely based on subjective evidence. Third, despite being a pharmacological study, the present study had no placebo control group. Fourthly, we did not evaluate the efficacy of duloxetine in PPI positive patients, and therefore, in our study, there is no comment on the effectiveness of duloxetine in PPI positive patients. Finally, the study had a relatively small patient population due to the administration of a large number of exclusion criteria.

In conclusions, our data show that in the early postoperative period, prophylactic administration of duloxetine, which started without regard to the positivity of PPI, is not an effective and rational method in patients undergoing radical prostatectomy. Instead, randomized, prospective and placebocontrolled studies are needed to investigate the efficacy of duloxetine in PPI-positive patients.

\section{Conflict of interest}

None to declare.

\section{Acknowledgments}

None to declare. 


\section{References}

1. Alan, C., Eren, A.E., Ersay, A.R., Kocoglu, H., Basturk, G., Demirci. E., 2015. Efficacy of duloxetine in the early management of urinary continence after radical prostatectomy. Curr. Urol. 8, 43-48.

2. Borges, R.C., Tobias-Machado, M., Gabriotti, E.N., Dos Santos Figueiredo, F.W., Bezerra, C.A., Glina, S., 2019. Post-radical prostatectomy urinary incontinence: is there any discrepancy between medical reports and patients' perceptions? BMC. Urol. 19,32 .

3. Boy, S., Reitz, A., Wirth, B., Knapp, P. A., Braun, P. M., Haferkamp, A., Schurch, B., 2006. Facilitatory neuromodulative effect of duloxetine on pudendal motor neurons controlling the urethral pressure: a functional urodynamic study in healthy women. Eur. Urol. 50, 119-125.

4. Collado Serra, A., Rubio Briones, J., Iborra Juan, I., RamónBorja, J.C., Solsona Narbón, E., 2011. Postprostatectomy established stress urinary incontinence treated with duloxetine. Urology. 78, 261-266.

5. Cornu, J. N., Merlet, B., Ciofu, C., Mouly, S., Peyrat, L., Sèbe, P., Yiou, R., Vallancien, G., Debrix, I., Laribi, K., Cussenot, O., Haab, F., 2011. Duloxetine for mild to moderate postprostatectomy incontinence: preliminary results of a randomised, placebo-controlled trial. Eur. Urol. 59, 148-154.

6. de Lira, G.H.S., Fornari, A., Cardoso, L.F., Aranchipe, M., Kretiska, C., Rhoden, E.L., 2019. Effects of perioperative pelvic floor muscle training on early recovery of urinary continence and erectile function in men undergoing radical prostatectomy: a randomized clinical trial. Int. Braz. J. Urol. 45, 1196-1203.

7. Filocamo, M. T., Li Marzi, V., Del Popolo, G., Cecconi, F., Villari, D., Marzocco, M., Nicita, G., 2007. Pharmacologic treatment in postprostatectomy stress urinary incontinence. Eur. Urol. 51, 1559-1564.

8. Fink, K.G., Huber, J., Wurnschimmel, E., Schmeller, N.T., 2008. The use of duloxetine in the treatment of male stress urinary incontinence. Wien. Med. Wochenschr. 158, 116-8.

9. Gresty, H., Walters, U., Rashid, T., 2019. Post-prostatectomy incontinence: multimodal modern-day management. Br. J. Community. Nurs. 24, 154-159.

10. Holm, H.V., Fosså, S.D., Hedlund, H., Schultz, A., Dahl, A.A., 2014. How should continence and incontinence after radical prostatectomy be evaluated? A prospective study of patient ratings and changes with time. J. Urol. 192, 1155-1161.

11. Kania, P., Wośkowiak, P., Salagierski, M., 2019. Preservation of continence in radical prostatectomy patients: a laparoscopic surgeon's perspective. Cent. European. J. Urol. 72, 32-38.

12. Nambiar, A. K., Bosch, R., Cruz, F., Lemack, G. E., Thiruchelvam, N., Tubaro, A., Bedretdinova, D. A., Ambühl, D., Farag, F., Lombardo, R., Schneider, M. P., Burkhard, F. C., 2018. EAU Guidelines on Assessment and Nonsurgical Management of Urinary Incontinence. Eur. Urol. 73, 596-609.

13. Li, J., Yang, L., Pu, C., Tang, Y., Yun, H., Han, P., 2013. The role of duloxetine in stress urinary incontinence: a systematic review and meta-analysis. Int. Urol. Nephrol. 45, 679-686.

14. Neff, D., Guise, A., Guralnick, M. L., Langenstroer, P., See, W. A., Jacobsohn, K. M., O'Connor, R. C., 2013. Duloxetine for the treatment of post-prostatectomy stress urinary incontinence. Can. Urol. Assoc J. 7, 260-262.

15. Nestler, S., Thomas, C., Neisius, A., Rubenwolf, P., Roos, F., Hampel, C., Thüroff, J. W., 2019. Long-term results of ProACT primary and repeat implantation for treatment of stress urinary incontinence in men. World J. Urol. 37, 1173-1179.

16. Pompe, R. S., Tian, Z., Preisser, F., Tennstedt, P., Beyer, B., Michl, U., Graefen, M., Huland, H., Karakiewicz, P. I., Tilki, D., 2017. Short- and Long-term Functional Outcomes and Quality of Life after Radical Prostatectomy: Patient-reported Outcomes from a Tertiary High-volume Center. Eur. Urol. Focus. 3, 615-620.

17. Sandhu, J. S., Breyer, B., Comiter, C., Eastham, J. A., Gomez, C., Kirages, D. J., Kittle, C., Lucioni, A., Nitti, V. W., Stoffel, J. T., Westney, O. L., Murad, M. H., McCammon, K., 2019. Incontinence after Prostate Treatment: AUA/SUFU Guideline. J. Urol. 202, 369-378.

18. Stanford, J. L., Feng, Z., Hamilton, A. S., Gilliland, F. D., Stephenson, R. A., Eley, J. W., Albertsen, P. C., Harlan, L. C., Potosky, A. L., 2000. Urinary and sexual function after radical prostatectomy for clinically localized prostate cancer: The Prostate Cancer Outcomes Study. JAMA. 283, 354-360.

19. Trofimenko, V., Myers, J.B., Brant, W.O., 2017. PostProstatectomy Incontinence: How Common and Bothersome Is It Really? Sex. Med. Rev. 5, 536-543.

20. Zahariou, A., Papaioannou, P., Kalogirou G., 2006. Is $\mathrm{HCl}$ duloxetine effective in the management of urinary stress incontinence after radical prostatectomy? Urol. Int. 77, 9-12. 